\title{
POLÍTICAS PÚBLICAS, PROCESO ORGANIZATIVO Y ADSCRIPCIÓN ÉTNICA EN UNA COMUNIDAD INDÍGENA DEL CONURBANO BONAERENSE ${ }^{1}$
}

\author{
María Laura WEISS ${ }^{2}$
}

\section{Resumen}

Este trabajo se propone analizar, desde la perspectiva de la Antropología Política, el conjunto heterogéneo de prácticas sociales, políticas y económicas que han llevado a cabo los miembros de "Nogoyin Ni Nala" desde los últimos años de la década de 1990 hasta el año 2007. Para ello, se retoma la creciente articulación de comunidades indígenas en el nivel local; el progresivo incremento de novedosas dinámicas de participación y visibilización de la "cuestión indígena" en la esfera pública expresado desde diversas políticas públicas; $\mathrm{y}$, asimismo, la articulación con organizaciones de carácter etnopolítico y sociales de base.

Palabras claves: Pueblos Indígenas; Ciudad; Políticas Públicas; Prácticas políticas; Identidad étnica

\section{Abstract}

The aim of this work is to analyse, from the perspective of Political Anthropology, the social, political and economic practices that members of "Nogoyin Ni Nala" have carried on since the late 1990s to the year 2007. In order to do so, we consider the growing articulation of indigenous communities in the local level; the progressive increase of new dynamics of participation and visibility of the "Indigenous Matter" in the public sphere - expressed by different public policies -; and their articulation with ethnopolitical and social organizations.

Key words: Indigenous Peoples; City; Public Policies; Political Practices; Ethnic identity.

\section{Résumé}

Dans cet article nous analysons, du point de vue de l'Anthropologie Politique, l'ensemble des pratiques sociales, politiques et économiques qui ont été réalisées par des membres de "Nogoyin Ni Nala" depuis la fin des années 1990 jusqu'à 2007. Pour ce

\footnotetext{
${ }^{1}$ La autora quiere agradecer al Dr. Sebastián Valverde y al Lic. Juan Engelman por su generosidad en la lectura y en las sugerencias brindadas para enriquecer y mejorar este trabajo. ${ }^{2}$ CONICET - FfyL-UBA/EHESS
}

Fecha de recepción del artículo:Octubre 2015

Fecha de evaluación: Noviembre 2015 
faire, nous revenons sur l'articulation croissante des communautés autochtones au niveau local, l'augmentation progressive de nouvelles dynamiques de participation et de visibilité de la "question indienne" dans la sphère publique - qui ont d'ailleurs été exprimées par différentes politiques publiques - et également sur son articulation avec les organisations ethnopolitiques et sociales de base.

Mots-clés: Peuples autochtones; Banlieue; Politiques Publiques; Pratiques politiques; Identité ethnique.

\section{Introducción $^{3}$}

Este trabajo se propone analizar, desde la perspectiva de la Antropología Política, el conjunto heterogéneo de prácticas sociales, políticas y económicas que han llevado a cabo los miembros de "Nogoyin Ni Nala" desde los últimos años de la década de 1990 hasta el año 2007 en que se conforma el "Consejo de Indígena de Almirante Brown", así como las estrategias desplegadas para efectivizar sus demandas y reivindicaciones. Para ello, se retoma la creciente articulación de comunidades indígenas en el nivel local; el progresivo incremento de novedosas dinámicas de participación y visibilización de la "cuestión indígena" en la esfera pública expresado desde diversas políticas públicas; y, por último, la articulación con organizaciones de carácter etnopolítico y sociales de base.

Este trabajo se enmarca dentro del cuadro teórico y analítico que brinda la Antropología Política, en tanto ésta posibilita un abordaje procesual y relacional de las configuraciones políticas y socio-organizativas que los indígenas despliegan en el ámbito urbano. Como abordaje teórico para este trabajo, será central retomar autores que han redefinido el concepto de Estado para examinarlo en sus formas amplias, culturales y cotidianas de acción, en tanto a través de sus dispositivos y agencias de regulación y administrativas definen y re-crean identidades y subjetividades (Abrams, 1988; Corrigan y Sayer, 1985; Joseph y Nugent, 2002; Lagos y Callas, 2007; Sharma y Gupta, 2006). Desde esta perspectiva, el Estado se conforma de un entramado complejo de instancias que comprenden no solo jurisdicciones y dominios fragmentados $\mathrm{y}$ superpuestos, sino también múltiples instancias de ejecución de acciones que pueden resultar contradictorias entre sí. Los autores mencionados permiten comprender que el Estado afirma mediante diversos medios - ya que, como señala William Roseberry (2000), lleva a cabo su acción no sólo mediante la policía y el ejército sino también a través de oficinas, rutinas, impuestos, permisos, papeles de registro, documentaciones, etc. - identidades y clasificaciones sociales con el objetivo de configurar un "marco discursivo común". Del estudio de Aradhana Sharma y Akhil Gupta (2006), se retoma

\footnotetext{
${ }^{3}$ En esta ponencia se han modificado los nombres de las personas entrevistadas para preservar su confidencialidad.

${ }^{4}$ Se propone este recorte temporal con el fin de otorgar un límite a la extensión del artículo y de las problemáticas analizadas. Por otra parte, los años posteriores a la conformación del "Consejo Indígena de Almirante Brown" ponen en juego nuevas experiencias organizativas y participativas entre las comunidades que lo componen (Comunidad Guaraní "Cacique Hipólito Yumbay", Comunidad del Pueblo Kolla "Guaguajni Jallpa", Comunidad Toba "Migtagan", Comunidad indígena del Pueblo Toba/Mocoví "Cacique Catán", Comunidad Indígena del Pueblo Mapuche "Juan Kalfulkura", Comunidad Toba/Mocoví "Nogoyin Ni Nala) y la Municipalidad de Almirante Brown - entre otras agencias estatales y actores sociales - que exceden el objetivo inicial de este trabajo.
} 
su proposición de reflexionar no solamente sobre la forma en que el Estado se reproduce en las prácticas cotidianas, en los encuentros, en las representaciones y performances culturales, sino también sobre la forma en que la población percibe la presencia del Estado y cómo se relaciona con éste.

El enfoque propuesto permite desarrollar una perspectiva abarcadora que recupera la agencia de los actores sociales, para dar cuenta de sus experiencias, capacidad de organización y de llevar adelante sus demandas, reivindicaciones y negociaciones con otros actores sociales. Esta capacidad de agencia se configura en el marco de relaciones sociales e interétnicas de carácter asimétrico y en su vinculación a las políticas implementadas desde diversas agencias estatales municipales, provinciales y nacionales (legislación, políticas de identidad, políticas productivas). Por otro lado, hacemos nuestra la propuesta de John Gledhill (2000) de pensar la agencia de los grupos subalternizados - como lo constituyen los pueblos indígenas - en el marco más amplio de relaciones de poder y los contextos socio-históricos específicos. El "marco discursivo común" al que refiere William Roseberry (2000) nunca resulta definitivo en su totalidad, ya que es atravesado por las controversias y las luchas que emprenden los sujetos sociales. En este sentido, de acuerdo con Daniel Nugent y Ana María Alonso (2002: 192).

"como 'caja de resonancia de un conjunto de relaciones de poder y procesos políticos' en el que se construyen y combaten formas de identidad y dominación diferentes pero intervinculadas, el Estado juega un papel protagónico en la producción de categorías socioculturales de clase, etnicidad y género".

Por lo tanto, esas categorías sociales, además de determinar la posición de los sujetos en diversas relaciones sociales y culturales, también influencian profundamente identidades socioculturales y las propias subjetividades de los sujetos (Lagos y Callas, 2007). Esta perspectiva nos posibilita comprender la vinculación entre el Estado, las comunidades y nucleamientos ${ }^{5}$ indígenas ya no como coacción sino de manera relacional. Así, es posible dirigir la mirada a la forma en que se inscribe la presencia del Estado y se rutiniza a nivel de lo cotidiano, en la aplicación de políticas públicas a través de sus agencias y organismos de gestión - independientemente de que los pueblos indígenas sean los sujetos directos/exclusivos de las mismas -.

La metodología escogida es de carácter cualitativo, y el trabajo etnográfico se ha realizado mediante entrevistas abiertas, y en profundidad, estructuradas y semiestructuradas a los integrantes de "Nogoyin Ni Nala", a funcionarios municipales, y a integrantes de otras comunidades/nucleamientos con las que comparten experiencias políticas y organizativas. Así, nos proponemos dar cuenta de las prácticas desplegadas y los sentidos producidos por los sujetos. No obstante, el análisis no se reduce a esta instancia microanalítica sino que comprende asimismo dimensiones de carácter estructural y procesual que posibilitan la consideración de las condiciones

\footnotetext{
${ }^{5}$ Se sigue la propuesta de Liliana Tamagno (2001) de utilizar el término nucleamiento ya que esta conceptualización permite dar cuenta de la heterogeneidad de las formas de asentamiento y de las entidades territoriales, que no siempre implican una continuidad territorial y/o étnica, como es el caso de Nogoyin Ni Nala. De esta manera, el término "comunidad" se puede comprender como una forma de organización social y política en transformación y en relación a un corpus legal que estipula sus requisitos - y las mismas pautas socio-organizativas que los pueblos indígenas accionan al organizarse bajo esa forma -, y no como un "dato natural" que define a estos pueblos.
} 
socioeconómicas y los procesos históricos de carácter más general en los que éstos se inscriben.

\section{Breve caracterización de "Nogoyin Ni Nala"}

La comunidad "Nogoyin Ni Nala" se encuentra asentada en diferentes localidades del partido de Almirante Brown, en el sur del Conurbano Bonaerense. En ella habitan aproximadamente 60 familias y, si bien no hay datos certeros de la población total, un cálculo estimativo arrojaría una cifra cercana a las 300 personas. En esta comunidad conviven diversos pueblos originarios - en su mayoría qom, luego mocoví y, en menor número, guaraníes y tonocoté - que han arribado desde mediados de 1960, en distintos momentos, desde el sur de la provincia del Chaco ${ }^{6}$. Las Tunas (en San Francisco Solano), Zabala, San Gerónimo, Santa Clara, Asunción, 2 de Abril (en Rafael Calzada) y Horizonte (en Claypole) son los barrios en los que sus miembros se encuentran asentados. Comparten estos espacios con sectores subalternos que no se adscriben como pertenecientes a alguna etnia en particular, con migrantes provenientes de países limítrofes, y con un buen número de guaraníes que no forman parte de la comunidad.

Según los datos aportados por el Documento Base de Análisis Territorial del Municipio de Almirante Brown (2009) ${ }^{7}$, la mayor presencia de hogares con Índice de Necesidades Básicas Insatisfechas (NBI) - que señala al menos algún factor de privación - se localizan en Ministro Rivadavia (30,2\%), San José (23,3\%), San Francisco Solano (21,4\%) y Rafael Calzada (20,7\%). Estos dos últimos, principalmente Rafael Calzada, corresponden a lugares en donde se encuentran localizados la mayor parte de quienes componen "Nogoyin Ni Nala". Asimismo, el estudio citado señala que, comparativamente, las cuatro localidades con mayor porcentaje de hogares con NBI muestran sus mayores carencias en el hacinamiento, el tipo de vivienda precario y en la capacidad de subsistencia.

\footnotetext{
${ }^{6}$ Hacia mediados de la década de 1960, llegó de Resistencia una pareja de los pueblos toba y guaraní que se asentó en la zona de Claypole en donde habitaban parientes de la mujer y luego adquirió los primeros cinco lotes en Rafael Calzada a un muy bajo precio. Fueron los migrantes internos, indígenas y no, quienes protagonizaron el proceso de expansión metropolitana entre la década de 1940 y 1970, al ir asentándose en "loteos populares". Así, grupos de ingresos bajos y medios fueron los que impulsaron el crecimiento y la expansión de la ciudad hacia la periferia y así se fue configurando el escenario territorial, demográfico y productivo de la Región Metropolitana de Buenos Aires (Pírez, 2005). En años venideros, la zona fue poblada con las familias de sus hermanos y primos, provenientes de la provincia del Chaco, principalmente de Colonia Aborigen Chaco, Napalpí y Quitilipi - Departamento homónimo -. Los mocoví que migraron lo hicieron desde Charata - Departamento Chacabuco - y Colonia Cacique Catán o Las Tolderías - a $22 \mathrm{Km}$ de la ciudad de Charata -. Algunos de quienes terminaron asentándose en la zona habían migrado con anterioridad a Dock Sud y Villa Iapi. Una explicación pormenorizada de este proceso de migración y del rol de las relaciones y redes de parentesco puede encontrarse en Weiss, 2013.

Los datos brindados por este Documento aunaron en su análisis los resultados del Censo Nacional de Población, Hogares y Vivienda del año 2001 (CNPHyV, 2001) e información local proveniente del procesamiento de información del Plan Jefas y Jefes de Hogares en el distrito, así como de entrevistas con informantes claves y documentos internos elaborados por el Municipio.
} 
Respecto a la reproducción social de la vida de los miembros de "Nogoyin Ni Nala", muchos de los asalariados, hombres y mujeres, estaban sujetos a una elevada precariedad laboral, de bajos salarios, contratos en negro, y de tipo temporal. Las mujeres y los hombres se insertaron principalmente en el sector privado. Las primeras lo hicieron como empeladas domésticas, de limpieza, textiles y en el cuidado de niños y ancianos, mientras que la actividad ocupacional de los segundos era mediante "changas" en el sector de la construcción, plomería, textiles. Algunos, con un mayor nivel de especialización - herrería, artesanías, textil - se sustentaban ofreciendo sus servicios o comercializando su producción a nivel local en distintas ferias o como contratados precarizados. La mayoría de ellos no recibían descuento por aporte jubilatorio ni aportaban por sí mismos, así como la mayoría no tenía cobertura de salud fuera del sistema de salud estatal.

A continuación, para analizar el despliegue de prácticas sociales, políticas y económicas llevado a cabo por los miembros del nucleamiento "Nogoyin Ni Nala" - en un recorrido que se inicia a fines de la década de 1990 hasta el año 2007 -, se retomarán las experiencias de vinculación con el Estado a través de diversas políticas sociales focalizadas en sectores vulnerables, así como con las políticas de identidad que posibilitaron que se perfilen nuevas vinculaciones entre los Pueblos Indígenas y el Estado. Asimismo, se dará importancia a las vinculaciones intercomunitarias y con diversas organizaciones (etnopolíticas; sociales). La propuesta consiste en poder comprender cómo las articulaciones y negociaciones con agencias estatales y sujetos sociales diversos han contribuido a un fortalecimiento de la identidad étnica en el nucleamiento "Nogoyin Ni Nala" durante ese período y las formas en que se movilizó esta identidad.

\section{I- Programas sociales de empleo y homogeneización de los beneficiarios}

A nivel nacional, durante la década de 1990 se profundizaron las políticas neoliberales de los años 1970 que habían ocasionado el colapso de la industrialización desarrollada desde mediados de la década de 1940. Una de las características del doble proceso de retirada y penetración del Estado (Catenazzi y Filc en Catenazzi, 2004) fue la desregulación económica y el recorte en las funciones estatales acompañado de la focalización de las políticas públicas sobre determinados sectores sociales. El paradigma neoliberal desde el que se puso en marcha la reforma del Estado se sustentó en una visión empresarial de la gestión pública y la transferencia de servicios públicos urbanos al sector privado o "tercer sector". Estas transformaciones tuvieron un impacto muy fuerte en los sectores subalternos de la sociedad e intensificaron la desigualdad social y la precarización de las condiciones de vida de grandes conjuntos sociales. Frente al aumento de los niveles de desempleo y pobreza, principalmente desde mediados de la década del noventa, se aplicaron programas de ayuda vinculados al desempleo, financiados por organismos de crédito internacionales como el Banco Interamericano de Desarrollo (BID) y el Banco Mundial (BM). En paralelo a estos programas, también se desarrollaron otros dirigidos a atender el déficit alimentario. Así, durante aquellos años, la política estatal frente a la desocupación estaba dirigida a la puesta en marcha de Programas de Ocupación Transitoria o "Planes"8 y la focalización

\footnotetext{
${ }^{8}$ El Banco Mundial denominó Workfare a los "planes" y a lo que desde el Estado se definen como políticas activas de empleo, cuyo requerimiento es el trabajo a cambio de beneficios
} 
del gasto social se orientó, entonces, sobre aquellos grupos sociales y aquellas regiones calificadas como "pobres" (Manzano, 2013).

Por otra parte, hacia mediados de la década de 1980 y durante los años 1990 se producen una serie de transformaciones en la jurisprudencia indígena, las cuales son expresión de procesos más amplios, que se encuentran vinculados con el auge y consolidación de movimientos étnicos en América y Argentina (Bengoa, 2007). En este proceso se profundiza el reconocimiento del Estado de los Pueblos Indígenas a los que se define como sujetos de derecho particularizados y diferenciados. Estos cambios no sólo fueron expresión y el marco en el que se afianzaron movimientos y organizaciones étno-políticas de diversa índole, sino que constituyeron un sustento y catalizador para su creciente desarrollo y acción". Por aquellos años, la "cuestión indígena" no sólo se volvía más visible a nivel nacional, sino que, lejos de replegarse sobre sí mismas, las organizaciones etnopolíticas, nucleamientos y comunidades comenzaban a replantear nuevas formas de vinculación, interpelación, negociación y confrontación con el Estado. Se afianza, de esta forma, una mayor capacidad por parte de los pueblos indígenas de constituirse en actores políticos.

En el caso de los sujetos de nuestro estudio, durante la década de 1990, su presencia en la urbe se encontraba invisibilizada ${ }^{10}$. En este sentido,

"La mayoría de la gente por acá, recién ahora están viendo que nosotros somos tobas, que somos descendientes, (...) la mayor parte cuando éramos chicos nadie conocía nada y ya te digo, como dice, nunca hubo una oportunidad de hablarlo con la gente de por acá... cuando estamos entre todos sí, era cuando nos juntábamos todos, (...) Y si bien estábamos todos diseminados en distintos lugares, siempre cuando nos juntábamos intentábamos hablar así. De recuerdos, de cuándo vinimos. Y ya te digo, mis papás no sé si por discriminación, si por ahí no se hablaba por miedo a que se te rían, o te carguen" (Mónica, qom, miembro de la comunidad).

Por lo que si bien se reconocían (autoadscribían) como pertenecientes a distintos pueblos indígenas (Tobas, Mocoví, Guaraní), esta identidad no era afirmada ni posicionada públicamente en el marco de relaciones interculturales asimétricas y en un medio como el urbano en el que el proceso de invisibilización adquiere un cariz particular y, a su vez, niega su identidad étnica tras estereotipos ("los cabecitas negras", "los negros", "los villeros") asignados a los sectores socioeconómicos subalternos.

monetarios. Como sostiene Manzano (2013), las recomendaciones de este organismo promovían la selección de beneficiarios entre familias pobres a cambio de una exigua ayuda monetaria por debajo de los salarios mínimos para desalentar a desocupados no pobres (The World Bank, 1998 en Manzano, 2013).

${ }^{9}$ En este arduo proceso, un punto de inflexión lo supuso, en la Reforma Constitucional de 1994, la incorporación del artículo 75, inciso 17, en el que se reconoce la preexistencia étnica y cultural de los pueblos indígenas en el país. Lo interesante es que durante la reforma constitucional de 1994 las organizaciones indígenas y asociaciones civiles ejercieron presión sobre los constituyentes, así como también, previamente, fue central esta capacidad organizativa durante la elaboración y sanción de la Ley Nacional $\mathrm{N}^{\mathrm{o}} 23.302$ "De Política Indígena y de Apoyo a las Comunidades Aborígenes".

${ }^{10}$ El imaginario dominante en la Argentina impuso un modelo de país blanco, formado por migrantes provenientes de Europa y en el que los "indios" o son vistos como parte de un pasado lejano, o continúan siendo definidos de forma esencializante, asociados al medio rural. 
No obstante, en primer lugar, se desplegaban relaciones de parentesco - más o menos próximas - entre los habitantes de los distintos barrios y entre ellos y quienes conformaban otros nucleamientos cercanos. En segundo lugar, estas relaciones de parentesco se expresaban en los viajes que emprendían a sus comunidades de origen - y las visitas de parientes desde éstas -. Esto nos permite visualizar un entramado de relaciones étnicas, a la manera de tramas identitarias, socioculturales, simbólicas y materiales translocalizadas que exceden los "límites" de una comunidad o un barrio.

Por otra parte, como señalamos en el apartado anterior, la problemática de la falta de acceso a la vivienda, el hacinamiento, los problemas de escasez de ingreso y la falta de continuidad laboral se constituían en las mayores dificultades de la población en esas localidades. Entonces, una serie de problemáticas fueron experimentadas por igual entre los habitantes más allá de su adscripción étnica. Algunos de los futuros miembros de "Nogoyin Ni Nala", al igual que sus vecinos, fueron beneficiarios del Programa Barrios Bonaerenses $^{11}$. Para ello, debían inscribirse en el municipio de Almirante Brown, a fin de recibir una escasa suma de dinero a cambio de una contraprestación. Ésta era usualmente determinada por dirigentes políticos de alcance local y consistía en trabajar en la ejecución de obras dentro del municipio dedicadas a la construcción de infraestructura barrial (iluminación de calles, construcción de viviendas y veredas, mantenimientos de escuelas y hospitales, barrido y limpieza) o a la formación/capacitación. Asimismo, durante la década del noventa, el reparto de alimentos también resultó un componente de las políticas de salud (Manzano, 2013). Muchas mujeres y adolescentes, madres y embarazadas, así como niños desde recién nacidos hasta los 6 años, habitantes de los barrios en los que se asienta el nucleamiento fueron integrados al Programa "Plan Vida" de la Provincia de Buenos Aires. Las "manzaneras ${ }^{12 " ~-~ t r a b a j a d o r a s ~ v e c i n a l e s ~ v o l u n t a r i a s ~ d e ~ l o s ~ d i s t i n t o s ~ b a r r i o s ~ v i n c u l a d a s ~ a ~}$ una coordinadora de manzaneras - fueron quienes se encargaban de la distribución de estos alimentos. Desde el año 1997, esta población también fue incorporada a un subprograma del anterior, llamado el "Plan Comadres", por lo cual, el control de la salud quedó a mano de las "comadres"13. Posteriormente, junto a vecinos de estos barrios, también se anotaron en el Plan Jefes y Jefas de Hogar Desocupados (PJyJHD) ${ }^{14}$,

\footnotetext{
${ }^{11}$ Este programa fue implementado durante la gobernación de Eduardo Luis Duhalde (quien gobernó en los períodos 1991-1995 y 1995-1999) en la provincia de Buenos Aires desde el año 1997. Los planes estaban dirigidos a jefes/as de hogar de familias sin ingresos, mayores de 16 años, desocupados, que no percibían prestaciones previsionales o seguro de desempleo y con tres o más personas a cargo (menores de 16 años, embarazadas, mayores de 65 años y/o discapacitados) y que, a su vez, residían en los barrios donde se ejecutaba el programa. Los Municipios adquirieron un rol protagónico en su implementación y la selección de los beneficiaros también era tarea de las áreas de cada municipio.

${ }^{12}$ La denominación "manzaneras" se debe a que su responsabilidad y red de acción territorial se extiende por entre cuatro a diez manzanas. Se designa a sus domicilios como "boca de estipendio" para la distribución de los alimentos.

${ }^{13}$ El Plan Vida fue un programa que se proponía disminuir el impacto de la pobreza en la población materno-infantil, en funcionamiento desde el año 1994. Junto a la entrega de alimentos, la otra línea de acción refería al control de la salud, ya que la trabajadora vecinal era también la encargada de estrechar los vínculos entre los beneficiarios y los centros de salud. El Plan Comadres se constituye como un programa complementario, dirigido a informar y colaborar con el control sanitario de las embarazadas beneficiarias (Dallorso, 2011).

${ }^{14}$ Durante el 2002 en la administración de Duhalde, como resultado del estallido económico y social del 2001, los programas sociales que se habían aplicado con anterioridad, se
} 
en los que el Municipio se encargó de coordinar la inscripción y registro de los posibles beneficiarios, y de ejecutarlos de forma descentralizada. Los beneficiarios percibían el "plan" a cambio de una contraprestación laboral (construcción y refacción de edificios públicos, tareas de apoyo en lugares públicos, edificios educativos y hospitales, atención de niños y ancianos) o actividades de capacitación, educación y/o formación profesional.

Como podemos ver, estas condiciones de reproducción social fueron compartidas por la población indígena y sus vecinos, en tanto sectores vulnerables sobre los que se focalizaron los programas sociales mencionados. En consecuencia, al ser sujetosdestinatarios por igual, se dio un proceso de homogeneización que invalidó lo étnico por el carácter y posición de ciudadanos en términos generales. Por otro lado, la implementación cotidiana de estos programas implicó la vinculación de los vecinos beneficiarios con diversos actores sociales que ocupaban una posición de poder a escala de la trama social local - la de los barrios - al ser éstos los encargados de instrumentar los planes, distribuir los recursos y constituir el nexo entre la instancia municipal y/o provincial y los beneficiarios. Este rol lo desarrollaron dirigentes barriales o líderes con anclaje barrial asociados a centros locales vinculados con partidos políticos - como las unidades básicas -, y a la Sociedad de Fomento Zavala-Las Tunas, o aquellos que poseían cargos dentro del Municipio, así como las manzaneras y comadres que desplegaban su intervención estatal a nivel territorial. Por otra parte, esta relación con el Estado era constituida desde su posición social como sectores subalternizados, "pobres" y desocupados y las demandas a los distintos ámbitos estatales, entre otras, se dirigían a la obtención de "planes" sociales.

\section{II- Beneficiarios y mediadores: Nogoyin Ni Nala y las políticas públicas}

Como hemos descrito, abordar la complejidad del caso analizado desde un planteo de tipo mecanicista-causal para explicar la relación entre poblaciones subalternizadas y alterizadas, -como lo son los Pueblos Indígenas - y el Estado, terminaría por invalidar la heterogeneidad y dinámica propia del espacio donde se localizan los nucleamientos y comunidades. De este modo, siguiendo a Virginia Manzano (2013), daremos importancia a las trayectorias sociales de los sujetos, a cómo resignifican tanto prácticas como representaciones, y cómo se establecen vínculos con el Estado y con otros sujetos sociales que conforman el entramado político y social del Conurbano Bonaerense, para comprender la trama social, política e identitaria que se configura y los sentidos que los sujetos otorgan a estas experiencias. A continuación, entonces, indagaremos en el carácter de estas tramas que vinculan sujetos sociales.

En cuanto a la participación de espacios etnopolíticos, algunos ancianos lo hicieron de manera esporádica en la Asociación Indígena de la República Argentina (AIRA) ${ }^{15}$.

reorganizaron en el marco de la Emergencia Económica, Alimentaria y Sanitaria establecida por el Poder Ejecutivo Nacional. El PJyJHD tenía como objetivo dar una ayuda económica a los jefes de hogar desocupados, cuyo monto era entre 150 y 250 pesos para familias con hijos de hasta 18 años, con hijos discapacitados y también para las mujeres embarazadas.

${ }^{15}$ La AIRA surgió en 1975 conformada a partir de diversos miembros provenientes de organizaciones etnopolíticas que acabaron por disolverse producto de la represión y de la persecución y encarcelamiento de sus dirigentes (Federación Indígena de Buenos Aires, Federación Indígena del Chaco, Federación Indígena de Tucumán). Como organización evitó la participación de no-indígenas en sus filas así como excluyó de su programa la definición 
Hacia fines del año 1998, un pariente de uno de los actuales referentes de la comunidad viajó del Chaco a Buenos Aires y decidieron encontrarse en ese lugar. Así, se entabló contacto con una de sus autoridades y se afianzó la vinculación con esta asociación. Esto constituyó, como se mostrará a continuación, un punto de inflexión en la organización y conformación de "Nogoyin Ni Nala" como comunidad. Desde ese momento, se configuró un paulatino proceso de transformación de las demandas y reivindicaciones, al igual que de las herramientas y articulaciones desde las que éstas se vehiculizan. De esta manera, se reactualizaron y generaron prácticas sociales, económicas y políticas sostenidas por los "sujetos".

Asimismo, esta vinculación posibilitó a los referentes "conocer personas a través de él [refiere a una de las autoridades de la Asociación] y que después con el tiempo pudimos contactarnos personalmente" (Luisa, qom, referente de la comunidad). De esta forma se logró contar con una serie de contactos no sólo a nivel de funcionarios del Estado en distintas dependencias (Ministerio de Desarrollo Social de la Nación, Ministerio de Trabajo, Empleo y Seguridad Social, Instituto Nacional de Asuntos Indígenas, por nombrar algunos), sino con otros referentes y miembros de otras organizaciones y comunidades del país.

La articulación de quienes luego se constituirían en referentes y miembros del nucleamiento estudiado con la AIRA posibilitó que se armase una delegación en la dirección particular de este referente; quien había quedado en situación de desocupado. En este sentido, dicho referente apuntaba,

“(...) Nosotros habíamos formado una sede acá en Calzada. Como nosotros no estábamos tampoco muy bien... cómo te puedo decir... recién habiamos empezado a trabajar ¿no? Primeramente íbamos a trabajar allá con ellos a Capital. O sea que nosotros cada vez que queríamos un proyecto teníamos que ir a Capital para que ellos nos hagan el proyecto." (Román, moqoit, referente de la comunidad).

Así, en el transcurso del año 2002, con la ayuda de una autoridad de la AIRA, se reunieron mediante Asamblea General "con el propósito de elegir la comisión que representará la 'Delegación de AIRA' con la denominación de 'Comunidad Toba de Rafael Calzada", y designar una Comisión Directiva a tal efecto, y que fue presentada ante la Municipalidad ${ }^{16}$. En este ensayo organizativo, por primera vez, escogieron un nombre que los integre y represente como un conjunto ante la sociedad global, las otras organizaciones y comunidades indígenas y el Estado. Esta experiencia de constituirse en subsede de la AIRA y de participar en sus espacios de debate y reuniones, les proveyó, como veremos, de un conjunto de saberes respecto a las herramientas y derechos a los que debían recurrir como Pueblos Indígenas.

Con la llegada de un nuevo gobierno nacional, en el año 2003, se produjo una paulatina redefinición de la política social, que se reflejó en la implementación de nuevos programas sociales, como el Proyecto Socioproductivo Manos a la Obra - orientado a emprendimientos productivos - y el Plan Familias - destinado a hogares en situación de vulnerabilidad -. Posteriormente, durante la presidencia de Fernández de Kirchner se

política coyuntural. Los propósitos de la AIRA - que se podrían sintetizar en tres conceptos: tierra, cultura y reconocimiento político - eran coincidentes con los del Movimiento Indio de toda América Latina (Bartolomé, 2003).

${ }^{16}$ Este es un extracto obtenido del "Acta Asamblea" labrado en esa ocasión. Los cargos fueron de Coordinador General, Secretario, Prosecretario, Tesorero, Secretario de Actas, dos Vocales Titulares y dos Suplentes y Fiscal. 
extendieron los programas que fomentan el trabajo cooperativo a través de Argentina Trabaja. El Programa de Empleo Comunitario (PEC) ${ }^{17}$ se implementó por primera vez en el año 2003. En ese momento, junto a miembros y autoridades de la AIRA, los referentes de la "Comisión" asistieron a reuniones informativas sobre el funcionamiento del programa en el Ministerio de Trabajo, Empleo y Seguridad Social. "Con [autoridad de la AIRA] aprendimos cómo hablar y relacionarnos, nos enteramos por [dicha autoridad] que existían" (Román, moqoit, referente de la comunidad) ${ }^{18}$.

En tanto sede de la AIRA, y a través de esta asociación, los referentes de la Comisión Nogoyin Ni Nala obtenían la planilla para inscribir a los propuestos beneficiarios que cobrarían los PEC. Para estos planes, se debía adjuntar la fotocopia del Documento Nacional de Identidad y del CUIL. El proyecto por el que debían brindar una contraprestación a cambio de los planes era un "ropero comunitario". Los vecinos beneficiarios se encargaban del reciclado de la ropa, su limpieza, arreglo, y posteriormente se la donaba todos los meses a cárceles, institutos de menores, hogares o centros de recuperación de personas con adicciones. Otras personas que percibían el plan en cuestión trabajaban en la limpieza de las calles de sus barrios. Los referentes de la Comisión y encargados de la subsede, todos los meses debían entregar la planilla con los datos de los que cobraban el Programa de Empleo Comunitario (PEC) a la Dirección de Empleo de la Municipalidad de Almirante Brown.

La forma en que convocaban a sus vecinos a inscribirse era la siguiente:

"Poníamos afiches de que se hacían planes PEC acá en la puerta de casa, comentábamos que perteneciamos a Pueblos Originarios y que podíamos darle una mano a ellos también. Era abierto a criollos e indígenas, para todos los que lo necesitaban" (Cecilia, qom, hermana de referente).

A partir de la puesta en funcionamiento de los PEC, se produjo una redefinición de las relaciones con los vecinos, especialmente con aquellos habitantes más próximos ubicados en los Barrios Zavala y Las Tunas, ya que en los límites del primero se encontraba en funcionamiento la sede de la AIRA. Por lo que,

"Si bien nos conocíamos por vecinos, muchos del Barrio Zabala-Las Tunas querían descubrir sus raíces y veían que vinieron de Pueblos Originarios. A los chicos jóvenes les gustaba saber. Venían a casa para reuniones de información, después también hacíamos comida, locro. A veces convocábamos a raíz de los planes pero también para informar cómo nos movíamos nosotros” (Luisa, qom, referente de la comunidad).

Esta confección de los listados con los datos de los aspirantes (en la que se llegó a inscribir más de 50 beneficiarios), cuya mayoría se adscribían como pertenecientes a

${ }^{17}$ El Programa de Empleo Comunitario (PEC) fue destinado a personas desocupadas y en situación de vulnerabilidad social, de baja calificación laboral, mayores de 16 años que no se encontraran recibiendo ninguna prestación o capacitación del gobierno nacional o algún gobierno local, salvo que la actividad del trabajador sea únicamente con respecto a transporte y almuerzo. Las empresas o instituciones participantes podían ser cualquier institución pública, organizaciones sin fines de lucro y todo tipo de cooperativas que, antes de realizar la solicitud, debían estar registradas en el Registro de Instituciones de Capacitación y Empleo (REGICE) en el Ministerio de Trabajo, Empleo y Seguridad Social.

${ }^{18}$ A modo de ejemplo de estos nuevos espacios de participación y de reunión con funcionarios estatales podemos citar en el año 2004 la participación en el Encuentro Intercultural de Pueblos Originarios, organizado por Derechos Humanos, Instituto Cultural, Gobierno de la Provincia de Buenos Aires. 
pueblos originarios (toba principalmente, pero también mocoví, guaraní, tonocoté) pero que también incluyó a algunos que no lo eran, permitió fortalecer la presencia de la "Comisión" en la zona y alcanzar una relativa visibilización de los indígenas asentados en estos barrios. Asimismo, fue la primera vez que se posicionaron como mediadores en la vinculación entre los vecinos y las instancias estatales intervinientes sobre esta población. Entonces, si bien este programa no tenía a los Pueblos Indígenas como su sujeto beneficiario, fue a través de su aplicación en el nivel local que la "Comisión" se comenzó a reconfigurar,

“(...) Al mover planes y todo se volvía político. Podían bajar más rápido, la prioridad la tuvimos por el trabajo que hicimos con el AIRA. Un puntero del barrio nos decía "¿Cómo pueden conseguir más plata [los PEC consistían en 100 a 150 pesos por mes], que nosotros?". Nosotros recibimos por 200 pesos. Siempre tuvimos respuesta a presentarnos como Pueblos Originarios" (Luisa, qom, referente de la comunidad)

Durante esos años también los referentes de la "Comisión" comenzaron a organizar la obtención de becas ${ }^{19}$ para estudiantes indígenas del último ciclo de la educación primaria y la educación secundaria a partir de un convenio entre el Ministerio de Desarrollo Social a través del INAI y el Ministerio de Educación, Ciencia y Tecnología. Para ello, a través de la AIRA, presentaron los formularios de solicitud ante el INAI. Así, como relata uno de los entrevistados, algunos dirigentes barriales les preguntaban

“CCómo puede ser que consigan becas para chicos?” Y no tuvimos ayuda.

"Dicen en la escuela que son hijos de caciques". Lo tomaban como broma pero querían saber qué estábamos haciendo" (Luisa, qom, referente de la comunidad). Sin embargo, el funcionamiento como delegación de la AIRA no prosperó debido a una disputa en torno a cómo y dónde se "bajaban" proyectos para microemprendimientos familiares ${ }^{20}$. En este sentido, uno de los referentes entrevistados relata:

"Con el tiempo hicimos una propia comunidad, nos abrimos de esa asociación.

Quisimos tener nombre nuestro, no depender de ellos para proyectos porque

estábamos sin personería” (Román, moqoit, referente de la comunidad).

Así fue como en el año 2005 se organizaron para hacer una segunda versión del acta, ahora sí, para presentarla ante el INAI e iniciar el trámite para la obtención de la personería jurídica como comunidad. "Los hermanos reunidos realizan la constitución formal de la comunidad, amparados por la ley Nacional Argentina $n^{\circ} 23.302$ y 24.071, artículo 75 inciso 17 y 22 de la Constitución Nacional" "21. Asimismo, se eligió como nombre Comunidad "Nogoyin Ni Nala" y se destacó la importancia de continuar avanzando en la "defensa de los derechos de los pueblos indígenas". El estatuto de la comunidad se armó con el asesoramiento de presidentes y referentes de otras

\footnotetext{
${ }^{19}$ Este convenio tiene lugar en el año 2003 y se firma como resultado de la creciente demandas de becas para el nivel secundario y para disminuir los índices de deserción. El INAI es el organismo responsable de la divulgación de la convocatoria a becas en las comunidades indígenas, distribución de formularios de solicitud en las mismas y de la articulación con organizaciones indígenas, entre otras funciones. Esta acción social del INAI como apoyo económico se originó en 1996 y de ahí en adelante, particularmente luego del convenio mencionado, el número de becas otorgadas fue en aumento. Estas becas se financian con recursos del Banco Interamericano de Desarrollo (BID) (Paladino, 2012).

${ }^{20}$ Presentaron distintos proyectos (panadería, herrería, carpintería, textil) a través de la personería jurídica de la AIRA como asociación al Ministerio de Desarrollo Social de la Nación. ${ }^{21}$ Extracto del Acta Constitutiva de la comunidad.
} 
comunidades que ya habían obtenido la personería jurídica (Comunidad Guaraní "Cacique Hipólito Yumbay", Comunidad del Pueblo Kolla "Guaguajni Jallpa", Comunidad Toba "Migtagan") con los cuales se habían contactado mediante participaciones en reuniones y eventos en la AIRA.

En este sentido, la búsqueda de una mayor autonomía en lo que respecta al manejo de los recursos económicos otorgados por políticas públicas sociales fue el motor y el objetivo inmediato que propulsó la decisión de armar una comunidad propia con una personería jurídica otorgada por el INAI. El ser "reconocidos" (aunque no formalmente) $)^{22}$ en tanto "[los funcionarios] saben que estamos acá" se significó como una forma de visibilizarse ante ellos y, por ende, de posicionarse en pos de una mayor participación en las negociaciones que establecían con éstos. Así, al reapropiarse de los elementos y formas desde los que el Estado los implicaba, este proceso de institucionalización y la obtención del reconocimiento del Estado nacional como comunidad indígena también se constituyó en una afirmación identitaria por parte de los miembros de "Nogoyin Ni Nala".

Por otra parte, se produjo una transformación de las demandas realizadas al Estado en relación a las políticas sociales que éste ejecutaba. A los reclamos por trabajo y "planes sociales" se sumó la búsqueda de generar contactos para poder alcanzar empleos de tipo cooperativos. Este objetivo perfiló la forma de vinculación con organizaciones sociales de base. Algunos miembros de "Nogoyin Ni Nala" participaron del Movimiento de Trabajadores Desocupados (MTD) Aníbal Verón y del Movimiento Territorial Independiente (MTI) de Almirante Brown en distintos momentos. En este último, lo hicieron a partir del contacto con un miembro guaraní, de este movimiento social, asentado en el barrio Zabala, que es parte de la organización comunitaria actual.

"En el local daban charlas de cómo visualizar el tema de cooperativas. Hablaban

con gente del barrio que iba a la reunión en el local del MTI. Nos daban

mercadería, pero nosotros ibamos no por bolsones sino para formar cooperativa.

Lo bueno es que nos llevó a conocer a gente del barrio que nos convoque a nosotros" (Román, moqoit, referente de la comunidad).

Participar de estos espacios se visualizó como un camino para poder iniciar el armado de cooperativas a través de estas organizaciones para lo cual asistieron a marchas y

$\mathrm{mi}^{22} \mathrm{El}$ trámite para la obtención de la personería jurídica y para ser registrados en el Re.Na.Ci continúa al día de hoy sin finalizarse, de ahí la referencia a lo no formal de este reconocimiento. Según una carta del INAI a la comunidad del año 2006, los miembros de "Nogoyin Ni Nala" no han podido cumplimentar los siguientes requisitos estipulados en la resolución del MDS 4811/96 respecto: ampliación de las tradiciones y costumbres que conservan en la Reseña histórica, la definición con exactitud de dónde se encuentra ubicada geográficamente la Comunidad, los mecanismos de remoción de autoridades de los Consejos (Directivo y Ancianos) y la designación de un Cacique que no figura como tal en el Acta. Sin embargo, consideramos interesante señalar que en años posteriores a los referidos en este trabajo, el reconocimiento como comunidad adquirió otro sentido para los protagonistas. Éste no se arraigó tanto en la obtención de la institucionalización y de una personería jurídica - que sí se realizó a través de otras formas organizativas - sino en las articulaciones y alianzas que pudieron desarrollar con otras organizaciones, comunidades y con funcionarios de distintas agencias estatales que les permitieron disputar el peso de la legalidad en los procesos de reconocimiento. Por otro lado, en este proceso entraron en contradicción los requisitos y tiempos propios de los organismos estatales con los tiempos, intereses y expectativas de la comunidad, que se reconfiguraban de acuerdo a las dinámicas propias de este tipo de relaciones sociales. 
piquetes frente al edificio municipal y en otras jurisdicciones. Sin embargo, al no lograrse ese fin, la articulación con estas organizaciones sociales fue de carácter esporádico. "No les convenía que estemos adentro de la coordinación porque querían mover los papeles ellos". La experiencia en la gestión de los planes PEC que los posicionó como agentes activos incentivó la agencia de los referentes al momento de fijar sus expectativas y pautar los términos de estas articulaciones con las organizaciones sociales mencionadas.

En el año 2006, junto a otros nucleamientos indígenas organizados como comunidades ${ }^{23}$ en el partido de Almirante Brown conformaron la "MESA de Organizaciones de Pueblos Originarios de Almirante Brown", siendo ésta una entidad registrada con personería jurídica como Asociación Civil sin Fines de Lucro, con el objetivo de lograr un espacio de "reuniones con hermanos para armar proyectos, trabajar juntos",24. Ésta se conformó con miembros bajo la figura de "socios" que eran elegidos como "representantes" para tal fin en las comunidades. La MESA se construyó como la entidad con la cual son reconocidas las comunidades indígenas del partido en conjunto, ya que la misma "trabaja a ritmo de los originarios y a nivel político. A veces desde el Municipio quieren trabajar con nosotros" (Román, moqoit, referente de la comunidad). Ésta se constituyó en el primer intento organizativo a nivel intercomunitario y a través de dicha asociación lograron tramitar diversos proyectos productivos (insumos para poner en funcionamiento herrerías, talleres de costura, panaderías) que eran bajados a las casas de los beneficiarios. Sin embargo, también, mediante la puesta en funcionamiento de la MESA y en las reuniones en las que participaban sus socios, se fueron delineando una serie temáticas en lo referente a "reconocimiento", "salud", "documentación", "planes sociales", "cultura" y "educación". A través de la puesta en discusión sobre estas cuestiones identificadas como prioritarias, el municipio fue constituido como el actor principal ante el cual formulaban sus demandas. Asimismo, en este espacio se rescataban como formas normativas de relación entre los representantes no sólo las obligaciones explicitadas en distintos artículos del estatuto de la MESA, sino toda una serie de valoraciones y significaciones respecto al carácter moral propicio de los representantes, "a la credibilidad y confiablidad de la palabra entre hermanos", en donde lo colectivo y "lo parejo" de la acción conjunta se entendía como la forma de "no crear divisiones entre los hermanos". Cuando estos criterios normativos se rompían, un Tribunal compuesto por los socios de la MESA tomaba una sanción disciplinaria. Ahora bien, no nos detendremos mucho más en este aspecto, salvo para destacar que en años posteriores los conflictos entre algunos de los representantes fueron en crescendo. Éstos no sólo fueron resultado de disputas en torno a la implementación de planes sociales o al manejo de dinero que se depositaba en la cuenta a través de alguna ONG, sino también a los diversos tipos de articulaciones políticas y de acceso a información importante que pudieran manejar. Otro factor a considerar son las trayectorias disímiles recorridas por los representantes, las diversas expectativas y las distintas capacidades para articular lo intracomunitario con este nivel más amplio de

${ }^{23}$ Estas comunidades son: Comunidad Indígena del Pueblo Guaraní "Cacique Hipólito Yumbay", Comunidad Indígena del Pueblo Kolla "Guaguajni Jall'pa”, Comunidad Indígena del Pueblo Toba "Migtagan", Comunidad Indígena del Pueblo Toba/Mocoví "Cacique Catan", Comunidad Indígena del Pueblo Mapuche "Juan Kalfulkura"

${ }^{24}$ La Mesa en cuestión posee un CUIT, el número de una cuenta bancaria y dos figuras elegidas entre ellos de presidente/a y vicepresidente/a y cuenta con registro en la Provincia de Buenos Aires y en el REPOC. 
negociaciones y vínculos. Con esto queremos brevemente señalar que los pueblos indígenas, al igual que otros grupos sociales, son actores sociales y políticos heterogéneos y contradictorios. A través de los espacios de negociación y vinculación que estos sujetos entablan con otros actores sociales y agencias estatales, la apropiación diferencial de recursos políticos y económicos así como la desigual puesta en despliegue de éstos por parte de los representantes o referentes puede generar y reproducir asimetrías que acaban por producir conflictos que menoscaban las capacidades organizativas y participativas de las organizaciones.

Por otro lado, por esos años, al igual que las otras comunidades, desde "Nogoyin Ni Nala" se emprendió un camino de puesta en escena de repertorios y prácticas culturales folklorizadas que permitieron configurar nuevos formas de vinculación con los vecinos pero también con funcionarios de la gestión municipal. En los primeros años, estas prácticas se hicieron principalmente a través de visitas a instituciones educativas y culturales de la zona a partir de demostraciones de artesanías para difundir su historia como pueblos indígenas, aunque posteriormente las estrategias de visibilización incluyeron otro tipo de actividades. De hecho, como resultado de la vinculación de la comunidad "Cacique Hipólito Yumbay" y el Municipio de Almirante Brown, se participó de una "Feria artesanal Indígena" organizada en una gran cadena de supermercados de la zona, para la exposición y venta de artesanías apoyada por el Ministerio de Desarrollo Social de la Nación a través de la Dirección de Promoción de la Comercialización, el Instituto Nacional de Asuntos Indígenas (INAI) y la Secretaría de Niñez, Adolescencia y Familia, en la que también participó el Sindicato de Comercio del municipio y el director del Plan Nacional Manos a la Obra. Durante los dos meses que duró este evento, miembros de distintos grupos étnicos lograron establecer una presencia continua de la población indígena en un espacio de gran circulación. Uno de los objetivos de esta feria era la comercialización de sus productos artesanales por lo cual funcionó como un medio de circulación y distribución de mercaderías tradicionales permitiendo comercializar la producción (tejidos, confección de ropa, herrería, etc.) sin intermediarios (Engelman, 2012). En la inauguración de esta actividad - realizada paradójicamente el 12 de octubre - estuvieron presentes funcionarios municipales y nacionales de alto rango y tuvo lugar en un contexto de avances en la lucha indígena y a una mayor capacidad por parte de los pueblos indígenas de constituirse en actores políticos capaces de lograr una injerencia relativa en la agenda estatal ${ }^{25}$.

En ese contexto, con la llegada de otro intendente en el año 2007, la gestión municipal buscó posicionarse como uno de los primeros municipios del conurbano que integraba la cuestión indígena a los Derechos Humanos en su programa político bajo el lema de "diversidad cultural". La vinculación entre las comunidades organizadas en la MESA con el municipio se hizo a través de la Subsecretaría de Derechos Humanos e Igualdad

${ }^{25}$ En el año 2005, el gobierno nacional lanzó el "Plan Nacional contra la discriminación" a través del Instituto Nacional contra la Discriminación (INADI) que en el 2006 es presentado en el Foro Permanente para las Cuestiones Indígenas de la Organización de las Naciones Unidas, en el cual se incluyó el diagnóstico de problemáticas que experimentan los "Pueblos Originarios" en el país y una serie de propuestas referidas al acceso a la justicia, capacitación y administración pública, derechos territoriales y restitución, desarrollo cultural, desarrollos sustentable de comunidades, INAI, etc. Otro logro de este proceso de movilización fue que en el año 2006, se sancionó la ley nacional 26.160 -y en el 2007 su decreto reglamentario- de Emergencia en Materia de Posesión y Propiedad de las Tierras que tradicionalmente ocupan las Comunidades Indígenas originarias del país. 
de oportunidades situada en la Casa de Cultura de Almirante Brown. La política de identidad desarrollada desde el municipio constituyó al sujeto indígena desde una alteridad esencializada cuyos valores e historias debían ser rescatados y a quienes se los implicó en términos de sus culturas y costumbres en la comunidad browniana desde un espacio de protagonismo en la gestión municipal $y$ en conjunto con toda la comunidad $^{26}$. Y esta esencialización en la representación de "lo indígena" se correspondió con una concepción de "diversidad cultural" reducida a otorgar financiamiento o facilitar el acceso al espacio público para la realización de eventos culturales o declarar de interés público alguna actividad o conferencia informativa brindada por los pueblos indígenas.

Sin embargo, en un petitorio al Municipio, ya elaborado en el año 2005 cuando se había conformado la Comisión Directiva de esta MESA, las demandas y los reclamos hechos por las comunidades que buscaban organizarse bajo esa forma consistían en "promover el patrimonio cultural y la educación bilingüe, la defensa y desarrollo de las comunidades, becas estudiantiles, cumplir y hacer cumplir el artículo 75 inciso 17 de la Constitución Nacional y la ley nacional 23.302 de políticas indígenas y apoyo a las comunidades y su complementaria, la 24.071, el convenio 169/89 de la OIT (Organización Internacional del Trabajo) y el decreto provincial $N^{\circ} 1859$ ”. El Municipio se constituyó como interlocutor y responsable de la aplicación a nivel local de los derechos ganados por los pueblos indígenas, tal como se sostiene en una de las actas "de exigir nuestros derechos a las autoridades gubernamentales del municipio de Almirante Brown”. Lo que es más importante aún, y lo será en años venideros cuando se abran nuevos espacios políticos y de participación de estas comunidades a escala municipal, el reclamo por un mayor emponderamiento en la toma de decisiones que los atañen se efectivizó en el pedido por una "mayor participación protagónica y activa debiendo el municipio prever los medios necesarios para garantizar la continuidad de nuestro proceso de organización". Este reclamo, que implicó como estrategia colectiva una reivindicación identitaria mediante prácticas de visibilización en los barrios, ante los vecinos, y ante el Municipio y sus funcionarios, se desarrolló a través de instancias organizativas como la constitución del "Consejo Indígena de Almirante Brown" en el 2007 - para trabajar políticamente sus problemáticas como pueblos indígenas de forma conjunta - y la "Coordinación de Pueblos Originarios" en el año 2008; esta última como organización institucionalizada y con un espacio físico dentro del Municipio.

\section{Palabras finales}

Así como la relación entre lo global y lo local no es unidireccional, tampoco lo es la manera en que se articulan las distintas políticas sociales y de identidad entre diversas agencias, escalas estatales y los sujetos destinatarios. Lo mismo puede decirse de la importancia de la legalidad, ya que si bien ésta ha catalizado y constituido un medio para la acción de los indígenas que interpelan al Estado desde un corpus jurídico que los define como sujetos de derechos específicos y diferenciales, las problemáticas que atraviesa la cuestión indígena no se resuelven sólo desde esa dimensión. Antes bien, no se procesan de manera lineal estas políticas ni esta legislación ya que se intersectan con las relaciones sociales que vinculan sujetos en lo local. Sostenemos que lo recién

\footnotetext{
${ }^{26}$ Web de la Subsecretaría de Derechos Humanos e Igualdad de Oportunidad de Almirante Brown.
} 
expresado posibilita otorgar complejidad y situar a los procesos organizativos y la elaboración de demandas, reivindicaciones y prácticas colectivas expuestas en su justo dinamismo y nivel de conflictividad.

A lo largo del tiempo, los programas sociales estatales focalizados sobre los sectores vulnerables, han variado desde aquellos de corte asistencialista a través de los programas sociales de ocupación transitoria ("planes") o el programa Plan VidaComadres - y su reformulación - hasta aquellos orientados a fomentar el trabajo cooperativo y la inclusión a través del trabajo de estos sectores de la sociedad, pero en ellos se homogeneizó y subjetivó a los beneficiarios como sectores subalternos, "pobres" y desocupados. Por otra parte, las políticas de identidad definidas a nivel nacional a través de las consecuentes transformaciones en el derecho indígena han históricamente moldeado a los pueblos indígenas como un sujeto de derecho y en términos de una alteridad diferencial. Asimismo, retomamos algunas líneas de la política de identidad implementada por el Municipio y cómo se aplicaron las políticas sociales a nivel local. Procuramos recuperar cómo los integrantes de "Nogoyin Ni Nala", a través de las articulaciones y negociaciones con otras comunidades, organizaciones étnicas y sociales y con agentes estatales generaron un interjuego entre políticas sociales y políticas de identidad para focalizarnos en las particularidades de su aplicación en el nivel local y urbano con el objetivo de indagar la forma en que éstas se intersectan.

De esta manera, nos interesó investigar cómo los referentes y miembros de "Nogoyin $\mathrm{Ni}$ Nala", mediante su vinculación con la AIRA, otras organizaciones y comunidades indígenas -entre las cuales se difundió información políticamente relevante- lograron constituirse como mediadores a la vez que beneficiarios en la ejecución de los planes Planes de Empleo Comunitario (PEC). Aunque este programa no tenía como población destinataria a la indígena, se produjo una reapropiación del mismo en la implementación de este programa lo que significó una redefinición de las relaciones con los otros habitantes de los barrios más próximos. Lo mismo puede decirse de los proyectos productivos obtenidos a través de la "MESA de organizaciones de Pueblos Originarios de Almirante Brown". En uno y otro caso, su ejecución y la red de relaciones sociales que éstos movilizaban, le permitió a la comunidad organizarse a un nivel local e inmediato, visibilizarse en este proceso, fortalecer su capacidad de agencia en tanto Pueblos Indígenas y disputar las redes de poder barrial por las que se encontraban (y encuentran) atravesados. En este proceso, las expectativas de la comunidad por una mayor autonomía en el manejo de los recursos económicos pero también políticos, se reflejaron en la búsqueda de emponderamiento y reclamos por la ampliación de los espacios participativos a la Municipalidad. La participación a través de la institucionalización es buscada para lograr un mejor posicionamiento dentro del ámbito local que les permita contar con mejores y más efectivas herramientas organizativas y no sólo direccionar su demanda sino contribuir a las políticas que los implican.

Asimismo, la política de identidad implementada desde el Municipio re-produjo una esencialización de la identidad de los pueblos indígenas del partido, al hacer hincapié en la exotización de la diferencia étnica y reificación cultural. Esta esencialización y politización de la identidad cultural genérica en tanto "Pueblos Indígenas" se constituyó en el sustento desde el cual los indígenas se vincularon con el Municipio pero también en el soporte en el cual se expresaron las disputas y conflictos. Estas prácticas en "Nogoyin Ni Nala" se hicieron en un primer momento a través de visitas a instituciones educativas y culturales de la zona a partir de demostraciones de artesanías para difundir 
su historia como pueblos indígenas, pero posteriormente las estrategias de visibilización incluyeron otro tipo de actividades como ferias de artesanías, eventos, fiestas, conferencias sobre derechos de los pueblos indígenas, que implicaban la organización conjunta de las comunidades. El afirmarse para sí mismos y a nivel público a partir de la representación de la "diferencia cultural" permitió renegociar supuestos y mecanismos propios de la práctica municipal anclados en los límites físicos y políticos del Municipio (definida como "acción localizada y municipalizada" por un funcionario municipal). En estas prácticas se ponían en juego y reproducían relaciones con comunidades por fuera del Municipio y con sus comunidades de procedencia en el Chaco (por ejemplo en la producción, circulación y venta de artesanías) por lo que trascendían los límites de una acción localizada, lo cual en años venideros se volvió un punto de conflicto cada vez más marcado.

Entonces podemos decir que, si bien los grupos indígenas se encuentran constreñidos por "mensajes y prácticas de dominación", al decir de Philip Corrigan y Derek Sayer (2005), que influencian y perfilan profundamente identidades socioculturales, éstos logran apropiarlos y resignificarlos. Sin embargo, la forma que adquiere la relación entre sujetos subalternizados y alterizados como los Pueblos Indígenas y el Estado no puede comprenderse como una reacción o mera internalización de los primeros a las políticas sociales y de identidad del segundo. Para lo cual analizamos los términos en que se da esa relación y cómo es resignificada, pero contemplando para ello las maneras en que los sujetos han desplegado sus representaciones y prácticas sociales y culturales. En este sentido, concluimos que a lo largo del proceso organizativo socio-político analizado se redefinió la manera en que los sujetos se vinculaban al Estado, ya que esa interpelación y la formulación de demandas no se conformó solamente en tanto sujetos subalternizados sino como Pueblos Indígenas, cuya identidad se constituyó en el sustento de su acción colectiva y política. Y en este proceso fueron centrales las articulaciones intercomunitarias y con la AIRA. Entonces, si bien la forma en que se organizaron políticamente y movilizaron por el fortalecimiento identitario y cultural implicó el manejo de planes y programas sociales y de identidad así como espacios colectivos de discusión política para conformar cooperativas, este proceso fue eminentemente étnico. A la demanda al Estado Nacional y Municipal por empleo, "planes sociales" y posteriormente por conformar cooperativas se yuxtapusieron nuevas formas de vincularse e interpelar al Estado - principalmente a nivel municipal - por un reconocimiento identitario, fortalecimiento cultural y participación política y conjunta respecto a las decisiones que los implicaban. En estas nuevas formas de demandar y vincularse al Estado, la identidad étnica fue la identidad que primó y que perfiló la manera en que vehiculizaron otras demandas. La capacidad de agencia de estos actores les posibilitó configurarse como sujetos políticos y sociales. Así, se fortaleció y reconfiguró su identidad como "Pueblos Indígenas" - en una escala más global e inclusiva, pero también en el nivel de pertenencia identitaria más inmediato - en tanto toba, mocoví, guaraní, tonocoté, y ya no sólo como "pobres" o "desocupados" o como sujetos jurídicos. Fue esta identidad la que cohesionó no sólo las relaciones intracomunitarias sino también intercomunitarias en la organización de la "Mesa de Organizaciones de Pueblos Originarios de Almirante Brown". Por lo cual, nos apartamos de una concepción instrumentalista de la identidad, para sostener que fue a través de la configuración de estos procesos organizativos que su identidad se pone en acción. Así ésta se politiza como etnicidad mediante la reivindicación de las identidades 
culturales en tanto práctica colectiva y política en el marco de relaciones interétnicas asimétricas.

\section{Bibliografía}

BARTOLOMÉ, M. A. (2003) "Los pobladores del "Desierto" genocidio, etnocidio y etnogénesis en la Argentina", Cuadernos de Antropología Social, No 17, págs. 162-189. BENGOA, J. (2007) La Emergencia Indígena en América Latina. Fondo de Cultura Económica, Santiago de Chile.

CATENAZZI, A. (2003) "Territorialidad y acción pública en la Región Metropolitana de Buenos Aires", Cuadernos de Investigación Urbanística, № 37, págs. 19-26.

CORRIGAN, P. y D. SAYER (1985) The Great Arch: English State Formation as Cultural Revolution. Basil Blackwell, Oxford.

DALLORSO, N. S. (2011) "Conflictos barriales en el Gran Buenos Aires: control social de la vida cotidiana de los sectores populares”, Sociológica, Año 26, № 73, págs. 109152.

Documento Base de Análisis Territorial del Municipio de Almirante Brown (2009) http://grupoideagoras.org/wp-content/uploads/Brown.pdf.

ENGELMAN, J. M. (2012). "Formas de organización social y liderazgo político en comunidades indígenas urbanas: estrategias de acceso al poder, construcción y mantenimiento en un caso de titulación y lucha por tierras comunitarias: Comunidad Tupí-Guaraní "Cacique Hipólito Yumbay". Tesis de Licenciatura. FfyL, Universidad de Buenos Aires.

GLEDHILL, J. (2000) Power and its disguises: anthropological perspectives on politics. Pluto Press, Londres.

JOSEPH, G. y NUGENT, D. (2002) "Cultura popular y formación del estado en el México revolucionario", en Aspectos cotidianos de la formación del estado. La revolución y la negociación del mando en el México moderno, G. Joseph y D. Nugent (COMP), México, Ediciones Era, págs. 31-52.

LAGOS, M. y CALLAS, P. (2007) "Introducción. El Estado como mensaje de dominación", en Cuadernos de Futuro. Antropología del Estado. Dominación y prácticas contestatarias en América Latina, M. Lagos y P. Callas (COMP), La PazBolivia, INDH/PNUD.

MANZANO, V. (2013) La política en movimiento: movilizaciones colectivas y políticas estatales en la vida del Gran Buenos Aires. Prohistoria ediciones, Rosario.

NUGENT, D. y A. M. ALONSO. (2002) "Tradiciones selectivas en la reforma agraria y la lucha agraria: Cultura popular y formación del estado en el ejido de Namiquipa, Chihuahua", en Aspectos cotidianos de la formación del estado. La revolución y la negociación del mando en el México moderno, G. Joseph y D. Nugent (COMP), Ediciones Era, México, págs. 175-212.

PALADINO, M. (2012) "Situación de los Pueblos Indígenas Argentinos en la Educación Superior. Datos de una primera aproximación" en Caminos hacia la educación superior: los programas Pathways de la Fundación Ford para pueblos indígenas en México, Perú, Brasil y Chile, Antonio Carlos de Souza Lima y Mariana Paladino (ORGS), e-papers, Río de Janeiro, págs. 226-260.

PÍREZ, P. (2005) "Descentralización demográfica y centralización económica en la Región Metropolitana de Buenos Aires", Población de Buenos Aires, vol. 2, N², págs. $29-44$. 
SHARMA, Aradhana y GUPTA, Akhil. 2006. "Introduction: rethinking theories of the State in an age of globalization", en The Anthropology of the State. A reader, A. Sharma y A. Gupta (eds.), Oxford, Blackwell Publishing.

ROSEBERRY, W. (2000) "Hegemonía y el lenguaje de la contienda" en Taller Interactivo: Prácticas y representaciones de la Nación, el Estado y la Ciudadanía en Perú. Lima, Instituto de Estudios Peruanos.

Subsecretaría de Derechos Humanos e Igualdad de Oportunidad de Almirante Brown.http://ddhhalmirantebrown.blogspot.com.ar/search/label/Pueblos\%20Originarios TAMAGNO, L. (2001) Nam Qom Hueta 'a Na dockshi Lma: Los tobas en la casa del hombre blanco. Identidad, memoria y utopía. Ediciones al Margen, La Plata.

WEISS, M. L. (2013) "Trayectorias migratorias y asentamiento de una comunidad indígena en el sur del Conurbano Bonaerense: el caso de la comunidad "Nogoyin Ni Nala" en Rafael Calzada", Intersticios. Revista Sociológica de Pensamiento Crítico, Vol. 7, N², Universidad Complutense de Madrid, Madrid, págs. 59-74. 